\title{
Special Focus on Next Generation Coatings for Gas Turbines
}

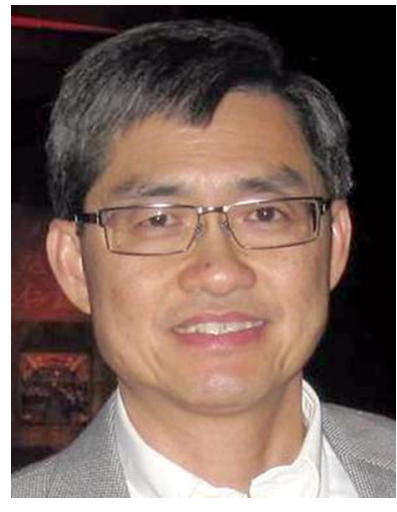

Y.C. Lau

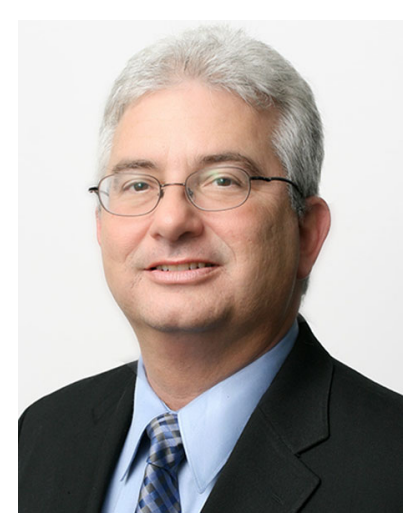

Mitch Dorfman

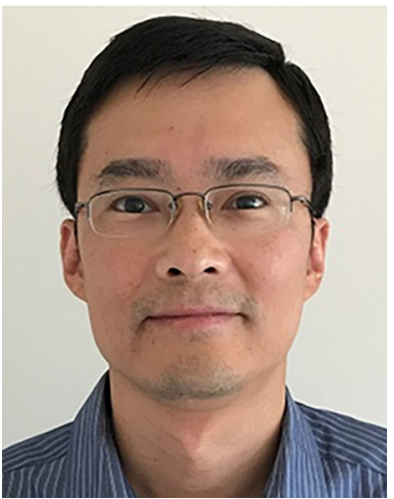

Li Li

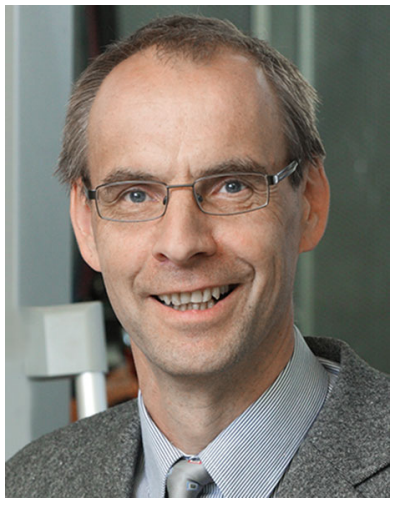

Robert Vaßen

This special issue of the Journal of Thermal Spray Technology (JTST) includes selected papers on Next Generation Coatings for Gas Turbines. This current issue includes 9 papers, and additional papers on this topic will appear in other regular issues.

Thermal spray coatings are vital to aircraft engines as well as large-scale industrial gas turbines (IGTs) for energy generation. With the introduction of silicon-based ceramic matrix composite (CMC) hot-section components to reduce fuel consumption in aircraft engines, thermal spray environmental barrier coatings are critically needed to protect CMC components from silica volatilization and surface recession in water-vapor containing combustion gas. Next generation IGTs will have approximately $65 \%$ combined efficiency with turbine inlet temperatures on the order of $1700{ }^{\circ} \mathrm{C}$, which will require durable and phase stable thermal-sprayed coatings.

This special issue contains the most recent advances in thermal spray technology for turbine applications,

including thermal barrier coating materials and architecture, oxidation and corrosion resistant coatings, abradable, robust coating manufacturing, and advanced thermal spray techniques, including, for example, suspension plasma spraying.

The Guest Editors would like to express their sincerest gratitude to the reviewers who provided invaluable feedback and to the authors who submitted manuscripts.

\section{Guest Editors}

Y.C. Lau

Retired, Formerly General Electric Power, USA

\section{Mitch Dorfman}

Oerlikon Metco, USA

Li Li

Rolls-Royce Corporation, USA

\section{Robert Vaßen}

Forschungszentrum Jülich, Germany 